\section{Multiple-electron excitation in X-ray absorption: a simple generic model. Erratum}

\section{Mervyn Roy, ${ }^{\star}$ J. D. Lindsay, S. Louch and \\ S. J. Gurman}

Department of Physics and Astronomy, University of Leicester, University Road, Leicester LE1 7RH, UK

Two typographical errors have been observed in the paper by Roy et al. [J. Synchrotron Rad. (2001), 8, 1103-1108]. Equation (16) should read

$$
\begin{aligned}
P(\hbar \omega)= & P(\infty)\left[\frac{\pi(2 n-1) !}{2^{2 n}(n-1) !(n+1) !}\right]^{-1} E_{B}^{n+1 / 2} \\
& \times \int_{0}^{E_{\max }} \frac{E^{1 / 2}}{\left(E_{B}+E\right)^{n+2}\left[1+t_{o}^{2}\left(E_{B}+E\right)^{2}\right]} \mathrm{d} E,
\end{aligned}
$$

while the correct form of equation (18) is

$$
\begin{aligned}
P(\hbar \omega)= & P(\infty)\left[\frac{\pi(2 n-1) !}{2^{2 n}(n-1) !(n+1) !}\right]^{-1} \\
& \times \int_{1}^{E_{p} / E_{B}} \frac{(X-1)^{1 / 2}}{X^{n+2}\left[1+\frac{1}{4}(n-1)^{2}\left(E_{B} / E_{p}\right) X^{2}\right]} \mathrm{d} X .
\end{aligned}
$$

These typographical errors do not affect our results or conclusions.

\section{References}

Roy, M., Lindsay, J. D., Louch, S. \& Gurman, S. J. (2001). J. Synchrotron Rad. 8, 1103-1108.
XAFS studies of nitrogenase: the MoFe and VFe proteins and the use of crystallographic coordinates in three-dimensional EXAFS data analysis. Erratum

\section{Richard W. Strange, ${ }^{a *}$ Barry E. Smith, ${ }^{b}$ Robert R. Eady, ${ }^{b}$ David Lawson ${ }^{b}$ and S. Samar Hasnain ${ }^{a}$}

a Molecular Biophysics Group, CCLRC Daresbury Laboratory, Warrington, Cheshire WA4 4AD, UK, and ${ }^{\mathbf{b}}$ Department of Biological Chemistry, John Innes Centre, Norwich NR4 7UH, UK

One of the authors was omitted in the published version of the paper by Strange et al. [J. Synchrotron Rad. (2002). 10, 71-75]. The full author list is given above. Since the acceptance of our paper, an atomic-resolution (1.16 $\AA$ ) structure of MoFe-protein has emerged [Einsle et al. (2002), Science, 297, 1696-1700]. We take this opportunity to update Table 1 of the paper, demonstrating improved agreement of the three-dimensional XAFS refinement with atomicresolution metrical information.

Table 1

Constrained refinements of the Mo $K$-edge EXAFS using a three-dimensional refinement approach.

In the first refinement, distances are kept at crystallographic values and Debye-Waller $\left(\sigma^{2}\right)$ values are refined; in the second refinement, the distances are also allowed to vary. A higher value than $0.03 \AA^{2}$ signifies that the atom is incorrectly placed and that little contribution to the EXAFS signal is made

\begin{tabular}{|c|c|c|c|c|c|c|}
\hline \multirow[b]{2}{*}{ Ligand } & \multicolumn{2}{|c|}{ First refinement } & \multicolumn{2}{|c|}{ Second refinement } & \multirow{2}{*}{$\begin{array}{l}\Delta R \\
(\AA)\end{array}$} & \multirow{2}{*}{$\begin{array}{l}1.16 \AA \\
\text { structure } \\
(\AA)\end{array}$} \\
\hline & $R(\AA)$ & $\sigma^{2}\left(\AA^{2}\right)$ & $R(\AA)$ & $\sigma^{2}\left(\AA^{2}\right)$ & & \\
\hline Mo-N(His) & 2.48 & 0.11 & 2.29 & 0.003 & -0.17 & 2.29 \\
\hline Mo-O5(homocitrate) & 2.29 & 0.11 & 2.14 & 0.001 & -0.16 & 2.18 \\
\hline Mo-O7(homocitrate) & 2.35 & 0.11 & 2.31 & 0.001 & -0.04 & 2.20 \\
\hline $\mathrm{Mo}-\mathrm{S} 1 B$ & 2.30 & 0.001 & 2.30 & 0.001 & 0.0 & 2.33 \\
\hline $\mathrm{Mo}-\mathrm{S} 3 B$ & 2.38 & 0.001 & 2.37 & 0.001 & -0.01 & 2.37 \\
\hline $\mathrm{Mo}-\mathrm{S} 4 B$ & 2.35 & 0.001 & 2.35 & 0.001 & 0.00 & 2.33 \\
\hline $\mathrm{Mo}-\mathrm{Fe} 7$ & 2.67 & 0.006 & 2.67 & 0.006 & 0.00 & 2.67 \\
\hline $\mathrm{Mo}-\mathrm{Fe} 6$ & 2.68 & 0.006 & 2.67 & 0.006 & -0.01 & 2.67 \\
\hline $\mathrm{Mo}-\mathrm{Fe} 5$ & 2.71 & 0.006 & 2.71 & 0.006 & 0.00 & 2.73 \\
\hline $\mathrm{Mo}-\mathrm{Fe} 2$ & 5.04 & 0.01 & 5.04 & 0.01 & 0.00 & 5.04 \\
\hline $\mathrm{Mo}-\mathrm{Fe} 3$ & 5.06 & 0.01 & 5.06 & 0.01 & 0.00 & 5.05 \\
\hline $\mathrm{Mo}-\mathrm{Fe} 4$ & 5.09 & 0.01 & 5.08 & 0.01 & -0.01 & 5.10 \\
\hline Fit index & & 12.4 & & 9.5 & & \\
\hline$R$ factor & $46 \%$ & & $37 \%$ & & & \\
\hline
\end{tabular}
$\Delta R$ is the difference in Mo-ligand distance from the crystallographic value averaged over the two independent $\alpha \beta$ units. The final column includes information from a $1.16 \AA$ structure (Einsle et al., 2002).

References

Einsle, O., Tezcan, A., Andrade, S. L. A., Schmid, B., Yoshida, M., Howard, J B. \& Rees, D. C. (2002). Science, 297, 1696-1700.

Strange, R. W., Eady, R. R., Lawson, D. \& Hasnain, S. S. (2003). J. Synchrotron Rad. 10,71-75. 